\section{Commentary: Treatment of aortic regurgitation in Behçet's disease: More than one way to skin a cat}

\author{
Manuel J. Antunes, MD, PhD, DSc
}

In a paper published in this issue of the Journal by Lee et al, ${ }^{1}$ from Korea, the authors describe a modified Bentall procedure using a subannular inverted graft and rapid deployment valve for aortic root reconstruction in a patient with cardiac Behçet's disease and aortic regurgitation. During the procedure, they also repaired a small subannular/ annular false aneurysm.

Behçet's disease is a rare disorder that causes blood vessel inflammation (vasculitis) throughout the body. It may be an autoimmune disorder and is more prevalent in countries of the Middle East and East Asia. In the aortic root, it is associated with extreme weakness of the vessel wall, annulus and valve, causing aortic regurgitation. Because of this, classical aortic valve replacement results in a very high rate of dehiscence of valve prostheses. Thus, use of a Bentall procedure, or one of its modifications, is recommended in this disease to decrease the risk of dehiscence. To suture the conduit below the annulus, in the normal tissues of the left ventricular outflow tract (LVOT), the authors inverted the valveless Dacron tube into the ventricular cavity. Then, after everting the conduit, a rapid-deployment prosthesis was implanted.

Conduit inversion and suture in the LVOT endocardium is a maneuver frequently used for homograft implantation in patients with infective endocarditis and aortic root abscesses. It facilitates the precision of the proximal anastomosis, whether in a continuous or in an interrupted suture fashion. Other modified Bentall operations for patients

From the Faculty of Medicine, University of Coimbra, Coimbra, Portugal.

Disclosures: The author reported no conflicts of interest.

The Journal policy requires editors and reviewers to disclose conflicts of interest and to decline handling or reviewing manuscripts for which they may have a conflict of interest. The editors and reviewers of this article have no conflicts of interest.

Received for publication Feb 22, 2020; revisions received Feb 22, 2020; accepted for publication Feb 24, 2020; available ahead of print April 1, 2020.

Address for reprints: Manuel J. Antunes, MD, PhD, DSc, Faculty of Medicine, University of Coimbra, 3000-075, Coimbra, Portugal (E-mail: mjantunes48@sapo.pt). JTCVS Techniques 2020;2:46-7

2666-2507

Copyright $@ 2020$ The Authors. Published by Elsevier Inc. on behalf of The American Association for Thoracic Surgery. This is an open access article under the CC BY-NCND license (http://creativecommons.org/licenses/by-nc-nd/4.0/).

https://doi.org/10.1016/j.xjtc.2020.02.039

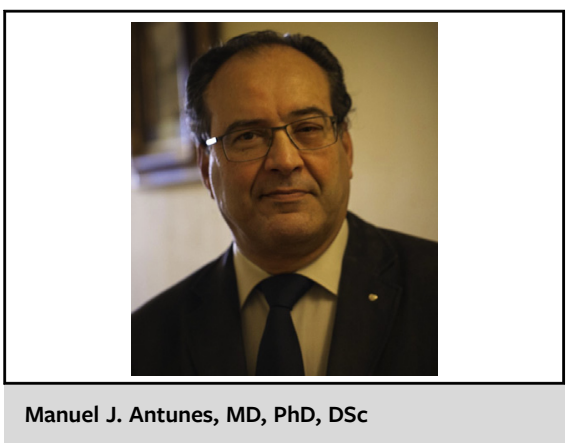

CENTRAL MESSAGE

Aortic regurgitation in Behçet's disease cannot be treated by classical AVR because of high incidence of prosthetic dehiscence. Several modifications of the Bentall procedure have been recommended.

with Behcet's disease have already been suggested by other authors. In the current case, use of a rapid-deployment valve was only a clever expedient to shorten the procedure. Hence, I do not see much novelty as a whole, but this report shows how much imagination is sometimes needed to achieve a good result.

The concept of subannular endomyocardial implantation of a valve prosthesis was previously introduced by Jung and colleagues. ${ }^{2}$ As Behcet's disease only affects the blood vessels, using the ventricular endocardium for anchorage makes sense and, as commented previously, this has been generally done in endocarditis with extensive destruction of the anulus. Azuma and colleagues ${ }^{3}$ had also described a "subannular ring reinforcement technique" to prevent valve detachment. In contrast, the use of a valved conduit in this disease was suggested by Ando and colleagues in 2000. ${ }^{4}$ Any type of conduit can be used, but I believe that this pathology is an appropriate indication for use of the homograft that may easily be inverted, as the authors did with the Dacron tube, to facilitate the proximal anastomosis. I am well aware that homografts may not be easily available in the regions in which this disease is more prevalent, but valved xenografts may also be a good alternative.

Finally, Lee and colleagues ${ }^{1}$ recognize the increased risk of complete heart block, as the muscle of the LVOT is included in the anastomosis. However, the 
incidence of atrioventricular block has been variable from report to report, and this complication is probably unrelated to the technical variation used, since they are all based on insertion in the subannular ventricular myocardium.

In summary, treatment of aortic regurgitation in patients with Behçet's disease is challenging. Classical prosthetic valve replacement is fraught by an unacceptably high risk of dehiscence. However, several alternatives have been proposed, all based on lower implantation in the LVOT of either valve prostheses, directly, or of valved conduits, in the form of a modified Bentall procedures. The principal virtue of this paper by Lee and colleagues ${ }^{1}$ is to remember us that there is often more than one way to skin a cat.

\section{References}

1. Lee C-H, Je HG, Ju MH. Modified Bentall procedure with a rapid deployment valve in cardiac Behçet's disease: a case report. J Thorac Cardiovasc Surg Tech. 2020;2:43-5.

2. Jung Y, Ahn BH, Lee KS, Jeong IS, Kim KH, Na KJ, et al. A novel solution to prosthetic valve dehiscence after aortic valve surgery in Behcet's disease. Interact Cardiovasc Thorac Surg. 2017;24:342-7.

3. Azuma T, Yamazaki K, Saito S, Kurosawa H. Aortic valve replacement in Behcet's disease: surgical modification to prevent valve detachment. Eur J Cardiothorac Surg. 2009;36:771-2.

4. Ando M, Sasako Y, Okita Y, Tagusari O, Kitamura S. Valved conduit operation for aortic regurgitation associated with Behçet's disease. Jpn J Thorac Cardiovasc Surg. 2000;48:424-7. 